$\mathrm{BP}$, biomass burning generally decreased to present across the Neotropics, with multi-centennial periods of high fire activity (e.g., 6 to 5 cal ka BP and ca. 2 cal ka BP) embedded in these long-term trends. Remarkably, records from the wettest regions of Amazonia (e.g., Lake Pata and Consuelo; Fig. 1) have no charcoal, suggesting that they remained fire-free over the last $21 \mathrm{ka}$. In contrast, Neotropical regions with high seasonality (e.g., Carajas, Brazil; Fig. 1) experienced more fires in the early to middle Holocene, when savanna replaced evergreen forest (Absy et al., 1991).

Neotropical ecosystems have experienced significant variability in biomass burning since the LGM but additional high-resolution charcoal records are needed to better establish regional fire-frequency trends. Simulating past changes in fire regimes with global and regional Earth System models will help assess the ability of these models to predict future changes in Neotropical fire regimes. Furthermore, studies of fire history from the tropics are highly relevant to issues of climate change and biodiversity conservation and can contribute to the development of appropriate fire-management policies (Horn and Kappelle, 2009).

\section{Acknowledgements}

We acknowledge the Global Palaeofire Working Group (GPWG) of the International GeosphereBiosphere Programme (IGBP) cross-project activity on FIRE for creating and providing access to the palaeofire charcoal database (Version 1). The GPWG is supported by the UK program QUEST (Quantifying Uncertainties in the Earth System), the Utah Museum of Natural History and IGBP projects iLEAPS, AIMES and PAGES, and the BRIDGE group at the University of Bristol. More information about the GPWG is avail- able on http://www.gpwg.org. We also thank the University of Oregon for its support.

\section{References}

Baker, P.A., Seltzer, G.O., Fritz, S.C., Dunbar, R.B., Grove, M.J., Tapia, P.M. Cross, S.L., Rowe, H.D. and Broda, J.P., 2001: The history of South American tropical precipitation for the past 25,000 years, Science, 291: 640-643.

Bush, M.B., Correa-Metrio, A., Hodell, D.A., Brenner, M., Ariztegui, D, Anselmetti, D., Gilli, A., Burton C. and Muller A.D., 2009: The Last Glacial Maximum: Central America. In: Vimeux, F., et al., (Eds), Past climate variability from the Last Glacial Maximum to the $\mathrm{HO}$ locene in South America and surrounding regions, Springer, Paris.

Cochrane, M.A. and Barber, C.P., 2008: Climate change, human land use and future fires in the Amazon, Global Change Biology, 15(3): 601-612.

Horn, S.P. and Kappelle, M., 2009: Fire in the páramo ecosystems of Central and South America. In: Cochrane, M. (Ed.), Tropical Fire Ecology: Climate Change, Land Use, and Ecosystem Dynamics, Berlin, Springer, 505-539.

Power, M.J., Marlon, J.R., Bartlein, P.J. and Harrison, S., 2010: Fire history and the global charcoal database: a new tool for hypothesis testing and data exploration, Palaeogeography, Palaeoclimatology, Palaeoecology, 291: 52-59.

For full references please consult:

http://www.pages-igbp.org/products/newsletters/ref2010_2.htm

\title{
Paleofires in southern South America since the Last Glacial Maximum
}

\author{
Patricio I. Moreno ${ }^{1}$, T. Kitzberger ${ }^{2}$, V. Iglesias ${ }^{3}$ and A. Holz ${ }^{4}$ \\ 1Department of Ecological Sciences and Institute of Ecology and Biodiversity, University of Chile, Santiago, Chile; email pimoreno@uchile.cl \\ ${ }^{2}$ Consejo Nacional de Investigaciones Científicas y Técnicas de Argentina and Laboratorio Ecotono, Universidad Nacional del Comahue, Bari- \\ loche, Argentina; ${ }^{3}$ Department of Earth Sciences, Montana State University, Bozeman, USA; ${ }^{4}$ Department of Geography, University of Colorado, \\ Boulder, USA
}

\section{Southern South American charcoal- and tree-ring-based fire histories suggest strong linkages between climate variability and regional fire regimes, with human influences having a more localized impact on fire occurrence.}

The diverse physiography, climate and biota of southern South America (SSA; $30-55^{\circ} \mathrm{S}$ ) offer the possibility of examining the pattern and causes of paleoclimate change and paleofire activity from subtropical to subantarctic environments, including the region of maximum surface wind speeds and frontal precipitation (48$50^{\circ} \mathrm{S}$ ) delivered by the Southern Westerly Winds (SWW). The southern Andes establishes an effective barrier to the advection of moist air masses across SSA and isolates Pacific and Atlantic moisture sources. An array of fire-history records along latitudinal and longitudinal gradients through SSA identifies the sensitivity and vulnerability of vegetation to past fire occurrence and the underlying climate and vegetation drivers of fire operating at different spatial and temporal scales.

At present, natural fire occurrence in SSA is driven primarily by tropical and extra-tropical influences on the SWW, as demonstrated by the correspondence of fires with synoptic patterns associated with El Niño-Southern Oscillation (ENSO) and the Southern Annular Mode (SAM). These modes of variability are captured by such indices as the Multivariate ENSO
Index and the Antarctic Oscillation Index (Garreaud et al., 2009; Villalba, 2007) (Fig. 1). During the positive (or warm) phase of ENSO, the southeastern Pacific subtropical high-pressure system weakens, allowing an equatorward deflection of the SWW to $\sim 30^{\circ} \mathrm{S}$. In conjunction with the development of an anomalously warm pool in the southeastern Pacific, this induces warm dry conditions in the mid latitudes (40-50 ${ }^{\circ} \mathrm{S}$ ) of western Patagonia, which promotes fire. During the positive phase of SAM, a low atmospheric pressure anomaly develops over Antarctica shifting the circumpolar vortex and subtropical highpressure system south and deflecting the SWW to $50-60^{\circ} \mathrm{S}$. The result is dry conditions conducive for fires between $35-43^{\circ} \mathrm{S}$. In addition, a positive SAM is correlated with a warm South Atlantic sea-surface pool that further enhances positive temperature anomalies over the mid-latitude eastern flanks of the Andes. The varying strength of these relationships in space (the correlation indices decline north and south along the Pacific side of the Andes) and time (the relationship remains significant only for the post-1977 warm phase of the Pacific Decadal Oscillation in the
1938-2004 record from northern Patagonia) suggests modulation of signals by nonstationarities and lower-frequency climatic (Enfield et al., 2001) and fire controls (Kitzberger et al., 2007). The complexity of climate drivers at different spatial and temporal scales argues for the need for a dense network of high-resolution paleofire reconstructions on both Andean flanks between $38-55^{\circ} \mathrm{S}$.

\section{Charcoal records}

The first charcoal-based fire histories in SSA were described by Calvin Heusser in Chile (Heusser, 1983) and Vera Markgraf in Argentina (Markgraf, 1983). Since then, fire history has been studied in many regions and most researchers suggest strong linkages between fire and climate, with human influences being more localized (e.g., Markgraf, 1993; Heusser, 1994; Heusser et al., 1999; Moreno, 2000; Huber and Markgraf, 2003; Haberle and Bennett, 2004; Whitlock et al., 2006; Markgraf et al., 2007; Abarzúa and Moreno, 2008). Regional syntheses of charcoal records have identified conspicuous multi-millennial trends in paleofire activity (Fig. 2) with low abundance of charcoal prior to $14 \mathrm{cal} \mathrm{ka} \mathrm{BP}$, an increase 
to prominent charcoal maxima from 1211.5 to $10.5-8$ cal ka BP, followed by a persistent decline between 8 and $3.5 \mathrm{ka}$ and a steady increase toward preindustrial values (Power et al., 2008). A spatio-temporal analysis of paleofire activity south of $35^{\circ} \mathrm{S}$ revealed widespread high fire activity between 12-9.5 cal ka BP, followed by latitudinal differentiation of fire activity between 9.5-6 cal ka BP and a heterogeneous fire pattern after 6 cal ka BP (Whitlock et al., 2007). These broad patterns suggest that insolation-driven changes in atmospheric circulation (i.e., variations in strength of the SWW and the southeastern Pacific subtropical high-pressure system) and the onset and strengthening of ENSO (Fig. 2) were drivers of regional paleofire activity, as well as vegetation change and renewed glaciation in the southern Andes (Moy et al., 2002; Huber et al., 2004; Moreno, 2004; Whitlock et al., 2006; Moreno et al., 2010).

A)

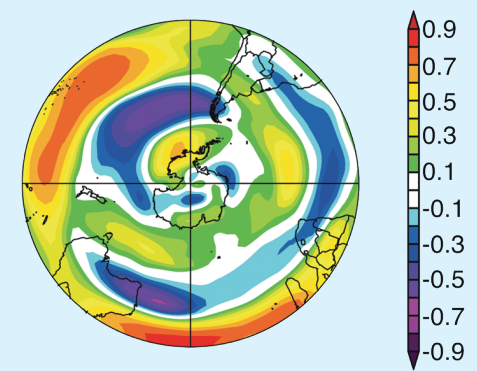

C)

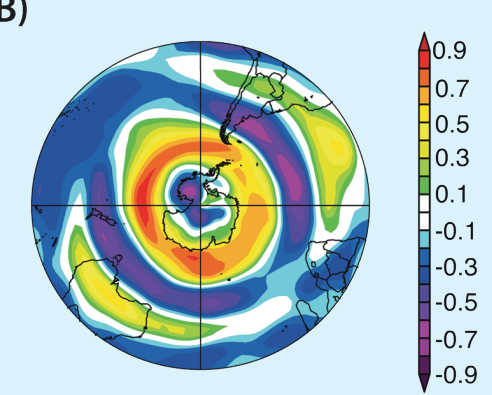

D)

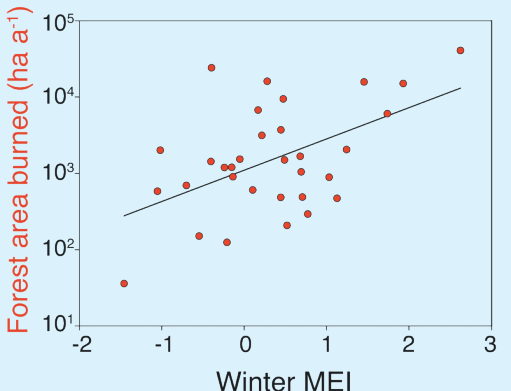

E)

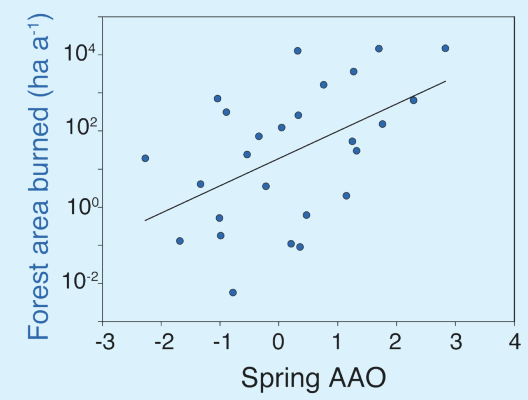

F)

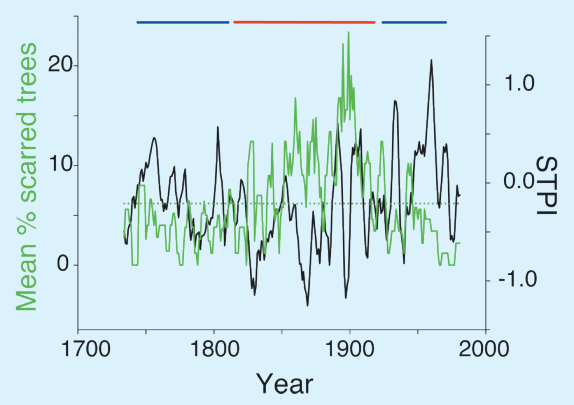

Comparisons of high-resolution charcoal records provide insights into decadal and longer variations in fire activity, including a separation of local fire events from regional fire activity. Figure 2 shows three Holocene charcoal records from the lake districts of southern Chile and Argentina (Abarzúa and Moreno, 2008; Whitlock et al., 2006). At multi-millennial scales, the records from Lago Melli (Chile) and Lago Mosquito (Argentina), show high fire activity in the early Holocene, in keeping with the SSA pattern for sites south of $35^{\circ} \mathrm{S}$. In contrast, Lago el Trébol (Argentina) records highest fire activity after $6 \mathrm{cal}$ ka BP. A shift from canopy fires to surface fires (inferred by increasing grass charcoal $\%)$ is noted east of the Andes at $\sim 7.8 \mathrm{cal} \mathrm{ka}$ BP (Lago Mosquito) and 6.8 cal ka BP (Lago el Trébol), suggesting wetter conditions. This change in fire regime coincides with lower fire activity (Lago Melli) and a multimillennial expansion of cold-resistant

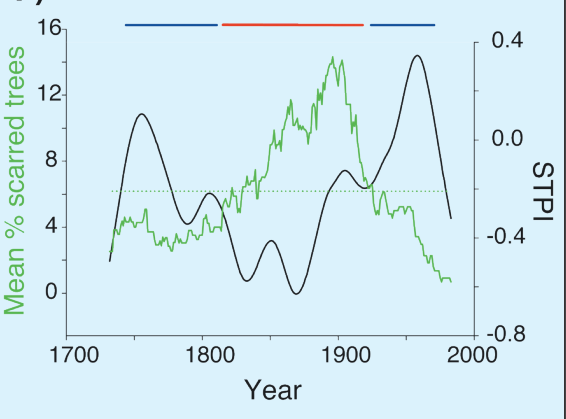

Figure 1: Correlation fields between (A) spring-summer Multivariate El Niño Southern Oscillation Index (MEI) and (B) Antarctic Oscillation Index (AAOl) with the $300 \mathrm{hPa}$ zonal wind (NCEP Reanalysis). Blue-violet fields indicate reduction (enhancement of westerly flow) during positive (negative) phases of the indices and vice versa for orange-red fields. C) Annual forest area burned in the Chilean Lake and River Districts (39-43ㅇ; 1972-2005, CONAF, 2010) in relation to winter MEI. D) annual forest area burned in the Argentinean Lake District (39-43'S, 1978-2004; Administración de Parques Nacionales, unpublished data) and spring $A A O(r=0.52$ and $r=051$, respectively, $P<0.01$ ). Yearly \% of scarred trees in the Lake District of Argentina (green) and the tree-ring reconstructed Summer Trans-Polar Index (STPI, black), expressed as (E) 5-a and (F) 49-a moving averages (modified from Veblen et al., 1999; Villalba et al., 1997). Horizontal blue and red bars illustrate multi-decadal to century-long periods of low and high fire, respectively.
North Patagonian trees on the Pacific side of the Andes (e.g., the Eucryphia-Caldcluvia/Podocarpaceae Index (ECPI) from Lago Condorito; Moreno, 2004). The regional patterns and individual site-based reconstructions suggest a shift to increased fires after 3.5 cal ka BP at many sites as well as more spatial heterogeneity in the occurrence of fire. The onset and subsequent intensification of ENSO at $\sim 6$ and $\sim 3$ cal ka BP, may explain these fire patterns. In addition, charcoal records suggest that fire activity peaked during the Medieval Climate Anomaly (1-0.8 cal ka BP) and then declined, in concert with a weakening of ENSO activity after $\sim 1$ cal ka BP (Fig. 2b).

\section{Fire scar records}

On shorter timescales, tree-ring-based fire-history networks from the Lake District of Argentina suggest widespread fire occurrence in the last 2-4 centuries as a result of human activity, and tropical and high-latitude climate drivers (Kitzberger and Veblen, 1997; Veblen et al., 1999). For example, large/synchronous fire events are related to winter-spring droughts of the late stages of strong La Niña events or hot summers following late-developing El Niño events. In the Araucaria-Nothofagus forests of the western Andes ( 39 $\left.9^{\circ} \mathrm{S}\right)$, positive ENSO phases are followed by warm dry summers and years of high fire activity (González and Veblen, 2006). Multidecadal variations of the Summer Trans-Polar Index, a measure of the circumpolar vortex strength and eccentricity (Villalba et al., 1997), influence long-term variations in fire occurrence (Fig. 1). Fire histories from $42-48^{\circ} \mathrm{S}$, based on the long-lived conifer Pilgerodendron uviferum, document the pervasive role of both ENSO and SAM in this cool-maritime hyperhumid sector of SSA (Holz, 2009; Holz and Veblen, 2009). Fire-history research is currently focused on coastal areas $\left(49-55^{\circ} \mathrm{S}\right)$ using P. uviferum, and along the eastern Andean flank using Nothofagus pumilio and Austrocedrus chilensis $\left(43-52^{\circ} \mathrm{S}\right)$, and Araucaria araucana $\left(38-40^{\circ} \mathrm{S}\right)$.

\section{Outlook}

Large gaps in our understanding of paleofires in SSA during and since the LGM suggest four directions for future investigation: (i) better calibration and crossvalidation of fire-scarred tree-ring records, high-resolution charcoal data, and documentary information; (ii) geographic expansion of the high-resolution paleofire network (charcoal and fire scars) in the region; (iii) time series analysis on multiple high-resolution charcoal records to enable reconstruction of centennial-scale climate 


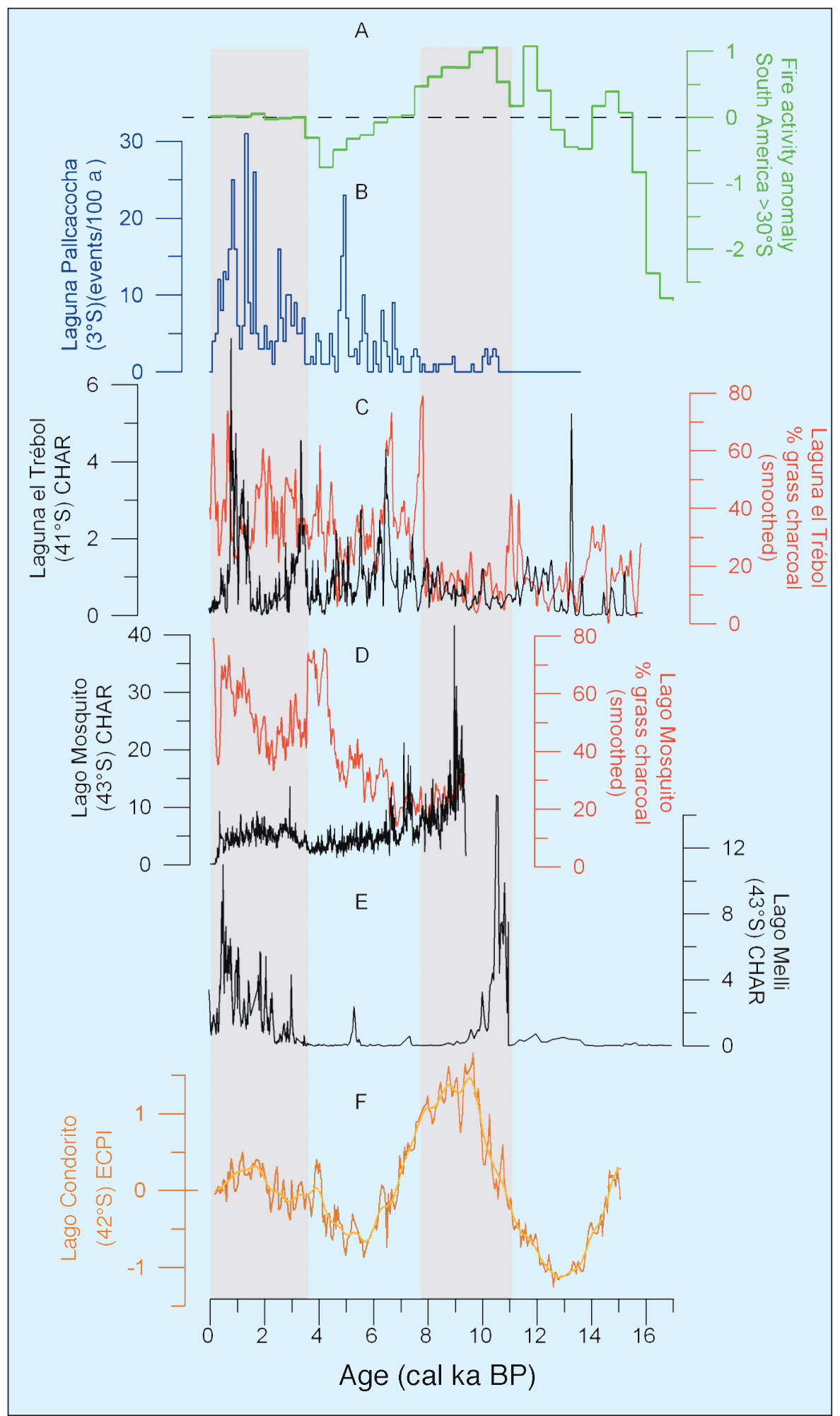

Figure 2: From top to bottom: $\boldsymbol{A})$ normalized and transformed charcoal data averaged at 500-a time steps over southern South America $\left(>30^{\circ} \mathrm{S}\right.$ ) (modified from Power et al., 2008); B) number of El Niño events/100-a inferred from the Lago Pallcacocha record (Ecuador) (modified from Moy et al, 2002); macroscopic CHAR (charcoal accumulation rates in particles $\mathrm{Cm}^{-2} a^{-1}$; black lines) from (C) Laguna el Trébol (Whitlock et al., 2006), (D) Lago Mosquito (Whitlock et al., 2006), and (E) Lago Melli (Abarzúa and Moreno, 2008). Percentage of grass charcoal particles (red lines) at Lago el Trébol and Lago Mosquito shows the increase in surface fires in the mid Holocene (Whitlock et al., 2006); and (F) the Lago Condorito palynological index (ECPl; orange line), which indicates multi-millennial timescale variations in precipitation of westerly origin since 14 cal ka BP. Positive anomalies indicate predominance of thermophilous (warmth-loving), drought-resistant Valdivian trees and relatively dry conditions and reduced influence of the Southern Westerly Winds (SWW). Negative anomalies represent the prevalence of North Patagonian rainforest taxa under cooler wetter conditions, implying stronger SWW influence. The vertical gray panels indicate the duration of a multi-millennial "dry" interval during the early Holocene (10.5-7.8 cal ka BP) and the period of high fire activity during the last $3.5 \mathrm{ka}$. and fire variability at the landscape level; and (iv) studies of the climatic and non-climatic interactions that lead to fire-regime changes under different climatic and landuse scenarios.

\section{Data}

The charcoal and tree-ring derived fire history data has been submitted to the International Multiproxy Paleofire Database (NOAA, NCDC. http://www.ncdc.noaa.gov/paleo/impd/paleofire.html)

\section{References}

Abarzúa, A.M and Moreno, PI 2008: Changing fire regimes in the temperate rainforest region of southern Chile over the last $16,000 \mathrm{yr}$, Quaternary Research, 69: 62-71.

Kitzberger, T. and Veblen, T.T. 1997: Influences of humans and ENSO on fire history of Austrocedrus chilensis woodlands in northern Patagonia, Argentina, Ecoscience, 4: 508-520.

Moreno, P.l., 2004: Millennial-scale climate variability in northwest Patagonia over the last $15000 \mathrm{yr}$, Journal of Quaternary Science, 19: $35-47$.

Whitlock, C., Bianchi, M.M., Bartlein, P.J., Markgraf, V., Marlon, J., Walsh, M. and McCoy, N., 2006: Postglacial vegetation, climate, and fire history along the east side of the Andes (lat 41-42.5 S), Argentina, Quaternary Research, 66: 187-201.

Whitlock, C., Moreno, P.I. and Bartlein, P., 2007: Climatic controls of Holocene fire patterns in southern South America, Quaternary Research, 68: 28-36.

For full references please consult:

http://www.pages-igbp.org/products/newsletters/ref2010_2.html 